\title{
A Rare Case of Possible, Food, Drug and Acrylamide Pharmacological Interactions
}

\author{
Restrepo C, Gómez V and Galvis Pareja D*
}

Universidad CES Medellin, Antioquia Colombia

\begin{abstract}
Fibromyalgia is a chronic disorder with a broad spectrum of clinical manifestations such as muscular weakness and pain, fatigue and sleep disturbances. In this case we describe a female patient, frequent tea consumer with a classic presentation of fibromyalgia, initially treated with paracetamol+caffeine, due to poor control of symptoms cyclobenzaprine was prescribed, after a few months the symptoms got worse and duloxetine was added to the pharmacotherapy, few days later her muscle pain and weakness worsened, this could be explained by either the acrylamide from tea that mimics the fibromyalgia symptoms or food-drug interactions. Palpitations, insomnia, restless legs syndrome and anxiety associated to a mild serotoninergic syndrome could be due to drug-drug interactions. The novelty of this article is the presence of neurotoxic acrylamide in tea and the interactions it may have, not only with disease but with conventional pharmacotherapy also. It is of relevance to raise awareness about the possible toxic compounds found in food.
\end{abstract}

Keywords: Fibromyalgia; Acrylamide; CYP-450; Glucuronidation; Caffeine; Transferase; Food-drug interaction; Duloxetine

\section{Introduction}

Fibromyalgia is a chronic disorder with confusing key features that may resemble other diseases such as chronic fatigue syndrome, some of its described characteristics are: pain, extensive muscular tenderness, cognitive complications fatigue and depression [1]. The therapy for such symptoms vary from doing some physical activity to a pharmacological treatment, this pharmacotherapy consists of an "off-label" use for old drugs such as antidepressants, i.e., tricyclic, serotonin and norepinephrine reuptake inhibitors, opioids, non-steroidal anti-inflammatory drugs, stereoidal anti-inflammatory drugs, growth hormone and some sedatives [2]. It is worth mentioning that cyclobenzaprine, a muscle relaxant, whose chemical structure resembles a tricyclic antidepressant, with an unknown mechanism of action is considered a good option for such treatment, in the same line go paracetamol+caffeine [1].

The pharmacotherapy for such disorder usually starts with one single drug and during the course of the treatment it might become necessary to escalate not only dosing but onto other drugs, in doing this, the chances of drug-drug interaction increase [3,4]. For example a patient may receive cyclobenzaprine, paracetamol+caffeine, the first one as a relaxant and the second to clearly mitigate the pain. In this scenario, the first drug-to-drug interaction to check for is in the pharmacokinetic range, the most common is related to drug metabolism, it is generally accepted that drugs undergo two pathways, the first one is called phase 1 reactions and consist mainly of hydrolysis and redox reactions, the remaining one is called phase 2 reaction and it involves conjugation reactions, in which drugs are chiefly conjugated to glucuronic acid $[2,5]$. Glucuronidation reactions are catalyzed by a family of enzymes known as uridine diphosphate-glucoronosyltransferases [6]. One main feature of phase 2 reactions is their role in the excretion of liphophilic drugs [2]. If there are two or more drugs present in a given organism, they might compete for any of the enzymes in whichever phase, as one drug would have more affinity for the enzyme than the other, this would displace it (PMCID: PMC1187712), and as consequence this could lead to a higher plasma concentration of the drug displaced, reaching toxic concentrations or accentuating their pharmacological effects.

Coffee is not the only source of caffeine, tea is another and welldocumented source of this compound, plus another concerning item is that acrylamide has been found in some types of tea, barley for example. Mugicha is an infusion of roasted barley grains, studies have found acrylamide in commercially available roasted barley grains in a range of $0.05-0.41 \mathrm{mg} \mathrm{kg}^{-1}$, mean: $0.24 \mathrm{mg} \mathrm{kg}^{-1}$, SD: $0.08 \mathrm{mg} \mathrm{kg}^{-1}$ and RSD: $35 \%$ [3,7]. The concentration of acrylamide found in teabags was $0.17 \mathrm{mg} \mathrm{kg}^{-1}$; this concentration appeared to increase with a higher simmering time [8].

The neurological effects described for acrylamide for single oral doses are in the range of $126 \mathrm{mg} / \mathrm{kg}$ in rats and rabbits and $100 \mathrm{mg} / \mathrm{kg}$ in dogs [4]. In a low-level occupational setting subchronic exposure the prominent neurotoxic effects found for acrylamide include numbness of hands and feet, skeletal muscle weakness and ataxia, and in an experimental setting acrylamide intoxication consisted of neurogenic autonomic dysfunction such as urinary retention, impaired vasomotor control and baroreceptor dysfunction [9]. Some other studies concluded in order to obtain clinical effect lower doses need to accumulate [4].

\section{Case Report}

Female patient, 42 years old, university professor, with a prior history of generalized musculoskeletal pain, muscle weakness, loss of limb strength, occasional headache, somnolence, asthenia and irritable mood, the symptoms increased by stress. At physical examination it was found generalized osteomuscular pain, 14/19 painful points, with preserved muscle tone and trophism, fibromyalgia diagnosis is done with WPI+SS score, autoimmune pathologies were discarded, acetaminophen 500 $\mathrm{mg}^{+}$caffeine $65 \mathrm{mg}$ every $8 \mathrm{~h}$ and cyclobenzaprine $10 \mathrm{mg} /$ day were prescribed, the patient reported improvement of symptoms for a few months but subsequently returned to consult because she presented an exacerbation of symptoms previously described associated with loss

*Corresponding author: David Andres Galvis Pareja, Universidad CES Medellin, Antioquia Colombia, Tel: 0057-4-4440555; E-mail: dagalvis@ces.edu.co

Received April 12, 2017; Accepted May 18, 2017; Published May 25, 2017

Citation: Restrepo C, Gómez V, Galvis Pareja D (2017) A Rare Case of Possible, Food, Drug and Acrylamide Pharmacological Interactions. Health Care Current Reviews 5: 196. doi: 10.4172/2375-4273.1000196

Copyright: (c) 2017 Restrepo C, et al. This is an open-access article distributed under the terms of the Creative Commons Attribution License, which permits unrestricted use, distribution, and reproduction in any medium, provided the original author and source are credited. 
of strength in left lower limb, working memory impairment, intense headache and burning pain in the maxilla and cervical area. At the physical examination the patient now presents $19 / 19$ painful points without signs of synovitis, so the treating MD decides to continue with acetaminophen $500 \mathrm{mg}$ plus caffeine $65 \mathrm{mg}$, cyclobenzaprine $10 \mathrm{mg}$ day and add duloxetine $30 \mathrm{mg}$ day. After treatment changes, the patient presented improvement in pain but worsening of headache, increased alteration of working memory (confusion), severe insomnia, nonrepairing sleep, restless legs syndrome and palpitations. It is important to note that throughout the evolution of the disease the patient was a frequent consumer of mugicha and Chinese tea.

\section{Discussion}

This case offers a variety of drug-drug interactions and the novelty of a possible cumulative toxicity and drug-toxic interaction generated by acrylamide (Figure 1). It is also important to note that the neurotoxicity generated by acrylamide confounds with the signs and symptoms of fibromyalgia (i.e., muscle weakness, numbness, etc.), so this makes it difficult to assess the neurological damage extension done by this toxic compound [9]. In this point, please recall that the patient also took duloxetine for her pain, which could have been triggered by acrylamide or by the pharmacological interactions (Figure 2). The patient also takes tea in unknown quantities, which also makes uncertain caffeine's concentration present in her body, besides the known quantity ingested with paracetamol (Figure 2). The pharmacokinetic interactions themselves may explain the patient's symptoms and signs, for instance duloxetine is metabolized via glucuronidation, acrylamide is metabolized by either phase 1 (CYP-450) or 2 reactions, in phase 2 , the enzyme involved is a glutathione transferase, paracetamol is metabolized by two enzymes in two independent phase two reactions glutathione and glucuronyl transferases, cyclobenzaprine is glucuronidated and caffeine is metabolized by CYP-450 (Figure 2) [3,10-12]

When the patient was taking all drugs simultaneously, duloxetine, paracetamol and cyclobenzaprine competed for the glucuronidation reaction, due to the symptoms described by the patient it is feasible to think that paracetamol displaced the other two drugs from the enzyme's binding site, which could have given the chance to the mild serotoninergic syndrome to occur. In itself acrylamide may account for all the symptoms presented by the patient, however caffeine is also metabolized by the CYP-450 isoenzymes, if they both competed

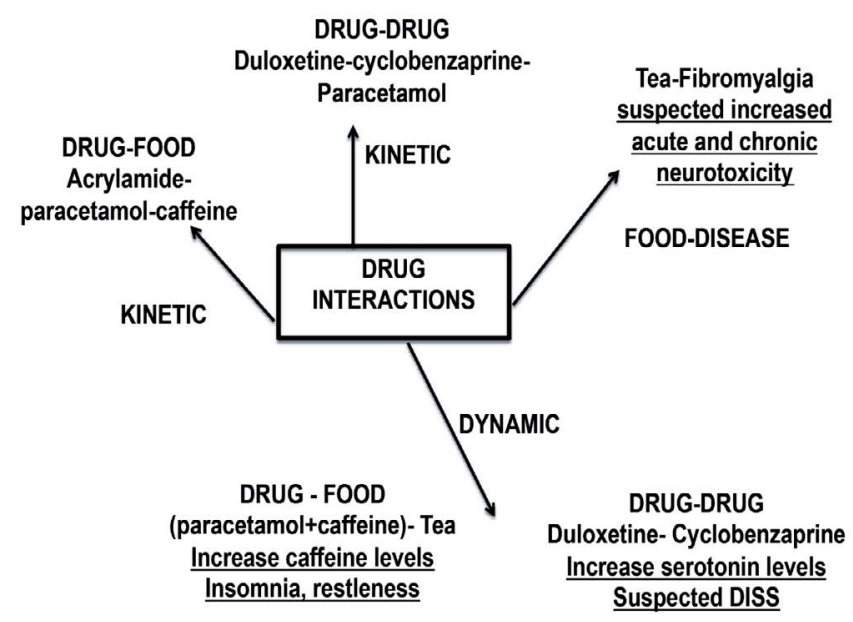

Figure 1: overview of drug, food and disease interaction
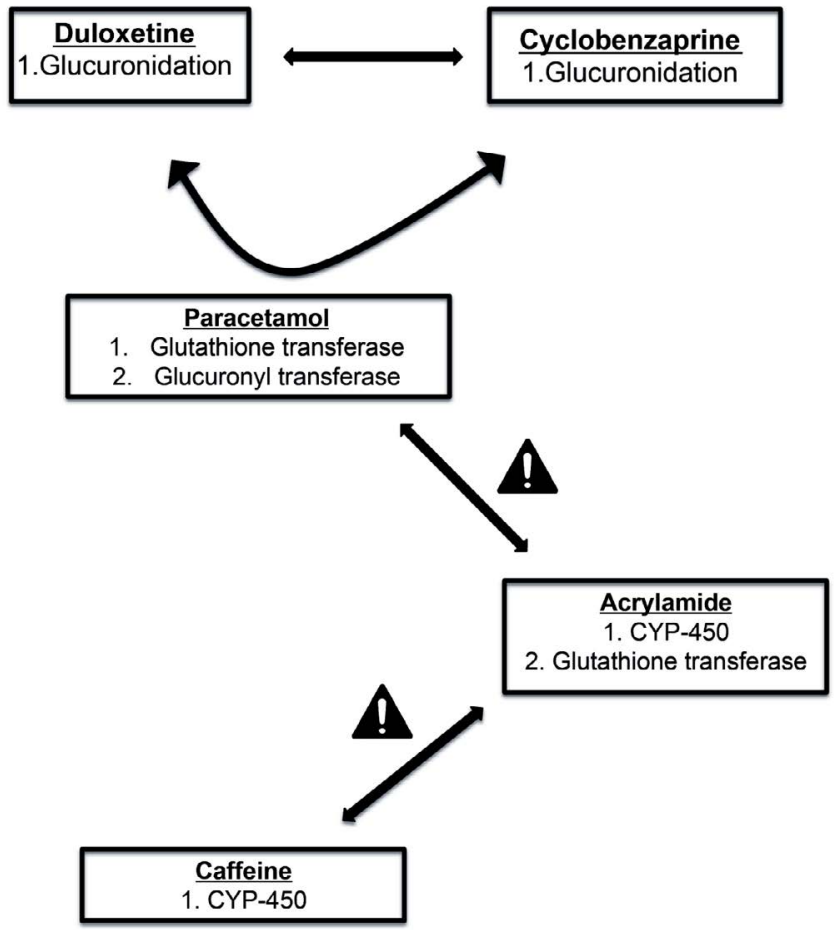

Figure 2: Summary of drug metabolism interaction.

for the same enzyme and acrylamide displaced caffeine, increasing its levels, the xanthine is known to produce even at lower doses restless legs syndrome and insomnia, that at some point, even in absence of paracetamol+caffeine formulation, the one contained in tea could explain these effects $[9,13]$. When considering the serotoninergic syndrome, it is important to note and clarify that for instance it may occur long time after discontinuation of the inducing drug, that some of its symptoms (i.e., mental status changes, increased muscle tone and spasms, restless legs, rigidity, shivering, tremor, insomnia and autonomic hyperactivity) are dismissed by physicians as the syndrome and that some of them can be caused by other drug/food such as caffeine, which in this case makes it more difficult to pinpoint the DISS or an adverse reaction generated by excess caffeine.

\section{Conclusion}

The novelty of this case lies in the role of food leading to pharmacological interactions; toxicity of itself or any of its compounds may lead to symptoms that resemble a disease. It is very important that healthcare professionals do not only consider drug-drug interactions in the pharmacotherapy but also the food that the patient consumes as a source of possible pharmacological interactions, like in this patient, whom presents a mild drug induced SS when the duloxetine was added, all these drug made part of the conventional treatment

This work is of importance because up until the writing of this report, it was not possible to find a similar case, the handling and preparing of food becomes a source not only of drug related interactions but it also becomes source of toxic compounds, which can mimic or exacerbate a disease and be a confounding factor for the treating physician to differentiate between the disease, the interactions and the toxic effect.

\section{Acknowledgement}

This section includes acknowledgment of people, grant details, funds, etc. 
Citation: Restrepo C, Gómez V, Galvis Pareja D (2017) A Rare Case of Possible, Food, Drug and Acrylamide Pharmacological Interactions. Health Care Current Reviews 5: 196. doi: 10.4172/2375-4273.1000196

Page 3 of 3

\section{References}

1. Suhr JA (2003) Neuropsychological impairment in fibromyalgia: Relation to depression, fatigue and pain. J Psychosom Res 55: 321-329.

2. Di Franco M, lannuccelli C, Atzeni F, Cazzola M, Salaffi F, et al. (2010) Pharmacological treatment of fibromyalgia. Clin Exp Rheumatol 28: S110-S116.

3. Lantz RJ, Gillespie TA, Rash TJ, Kuo F, Skinner M, et al. (2003) Metabolism, excretion, and pharmacokinetics of duloxetine in healthy human subjects. Drug Metab Dispos 31:1142-1150.

4. Trumic E, Pranjic N, Begic L, Bečić F (2012) Prevalence of polypharmacy and drug interaction among hospitalized patients: Opportunities and responsabilities in pharmaceutical care. Mater Sociomed 24: 68-72.

5. Xu C, Li CYT, Kong ANT (2005) Induction of phase I, II and III drug metabolism/ transport by xenobiotics. Arch Pharm Res. 28: 249-268.

6. Jancova P, Anzenbacher P, Anzenbacherova E (2010) Phase II drug metabolizing enzymes. Biomed Pap Med Fac Univ Palacky Olomouc Czech Repub. 154: 103-116.
7. Chen Z, Lin Z (2015) Tea and human health: Biomedical functions of tea active components and current issues. J Zhejiang Univ-Sci B 16:87-102.

8. Mizukami Y, Yoshida M, Ono H (2016) Acrylamide elution from roasted barley grains into mugicha and its formation during roasting. Food Addit Contam Part Chem Anal Control Expo Risk Assess. 33: 225-235.

9. Erkekoglu P, Baydar T (2003) Acrylamide neurotoxicity. Nutr Neurosci. Nutr Neurosci 17: 49-57.

10. Friedman $M(2003)$ Chemistry, biochemistry and safety of acrylamide. A review. J Agric Food Chem 51: 4504-4526.

11. Tujios S, Fontana RJ (2011) Mechanisms of drug-induced liver injury: From bedside to bench. Nat Rev Gastroenterol Hepatol 8: 202-211.

12. accessdata.fda.gov/drugsatfda_docs/label/2003/017821s045lbl.pdf

13. Kot M, Daniel WA (2007) Effect of cytochrome P450 (CYP) inducers on caffeine metabolism in the rat. Pharmacol Rep PR 59: 296-305. 